\title{
硝酸溶液を用いた $\mathrm{Si}$ 表面上への $\mathrm{SiO}_{2}$ 酸化薄膜の 低温形成と酸化膜の電気特性評価
}

\author{
松本健俊・アスハ*・今村健太郎・小林 光 \\ 大阪大学産業科学研究所, CREST-JST 业567-0047 大阪府茨木市美穂ヶ丘 8-1
}

(2008 年 3 月 13 日受理)

\section{Low Temperature Formation of $\mathrm{SiO}_{2}$ Thin Films by Nitric Acid Oxidation of $\mathrm{Si}$ and Electrical Characterization of the Film}

\author{
Taketoshi Matsumoto, Asuha*, Kentaro Imamura and Hikaru Kobayashi \\ ISIR, Osaka University, CREST, Japan Science and Technology Organization, 8-1 Mihogaoka, Ibaraki, Osaka 567-0047
}

(Received March 13, 2008)

\begin{abstract}
Formation of thin gate insulators with high electrical characteristics is a key technology to achieve high performance of semiconductor devices in the next generation. As for thin film transistors (TFTs) used in liquid crystal displays (LCDs), a new low temperature gate oxide formation technique is required to provide homogeneous gate insulators on rough poly-Si surfaces with substrate glass. We have developed two different methods for nitric acid oxidation of $\mathrm{Si}$ (NAOS) at $120^{\circ} \mathrm{C}:$ i) one-step NAOS using azeotropic nitric acid solutions (68wt\%) to form ultrathin (i.e., $\sim 1 \mathrm{~nm}$ ) $\mathrm{SiO}_{2}$ layers with an extremely low leakage current density, and ii) two-step NAOS using $\sim 40$ and $68 \mathrm{wt} \%$ nitric acid solution to form thick (i.e., $\geq 10 \mathrm{~nm}$ ) $\mathrm{SiO}_{2}$ layers. A progress in the NAOS techniques is outlined in this report.
\end{abstract}

KEYWORDS : silicon, silicon oxide, nitric acid, insulating films, transistor

\section{1.は じめに}

大規模集積回路（LSI, Large Scale Integration）の微細 化の過程で, トランジスタを構成するゲート絶縁膜の薄 膜化が進んでいる。LSI の基本構造である金属-酸化膜半導体電界効果トランジス夕 (MOSFET, Metal-OxideSemiconductor Field Effect Transistor）は，Fig. 1のような 構造で, ゲート電極の電圧によりソース電極とドレイン 電極の間に流れる電流を制御しており，デジタルデバイ スではいわばスイッチのような役割をしている。本来 は, ゲート絶縁膜を通って電流が漏洩してはならない が，絶縁膜の薄膜化に伴い，このリーク電流密度が増加 している。これにより, デバイス動作が不安定になった

E-mail : tmatsumo@sanken.osaka-u.ac.jp

* 現所属 : Chemistry \& Environment Science College of Inner Mongolia Normal University, 295 Zhaowudalu, Hohhot 010022, China
り, 不能になったりする致命的な問題や, 消費電力の増 加という重大な問題が起きている。

液晶ディスプレイ（LCD, Liquid Crystal Display）に用 いられている多結晶シリコン（poly-Si）上に形成した薄 膜トランジス夕（TFT, Thin Film Transistor）において も，ゲートリーク電流の低減に関する研究が盛んに行わ れている。 poly-Si は, アモルファス $\mathrm{Si}(\mathrm{a}-\mathrm{Si})$ のレーザー アニールにより形成するが, a-Si が結晶化する時に多く の結晶界や表面に凹凸（リッジ）が生成し，この表面に 均一な $\mathrm{SiO}_{2}$ 薄膜を形成することは困難である。さらに, 基板が低融点ガラスで $400^{\circ} \mathrm{C}$ 以下での低温酸化が必要な ため, Si 単結晶上で一般的に用いられる熱酸化膜に匹 敵する性能を容易には達成できない。現在は, TFT 用 ゲート絶縁膜の形成に, 低温で $\mathrm{SiO}_{2}$ 薄膜を形成できる 気相蒸着法 (CVD, Chemical Vapor Deposition) が用いら れているが，十分なリーク特性を得るためには 50〜100 $\mathrm{nm}$ の膜厚のゲート絶縁膜を必要としている。この原因 


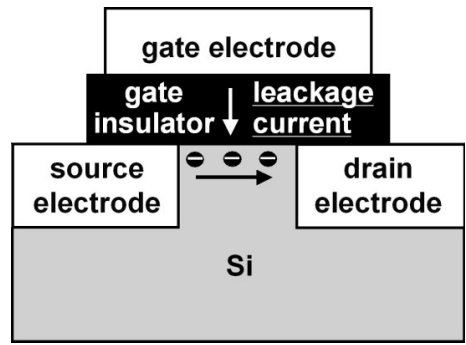

Fig. 1. Structure of MOSFET.

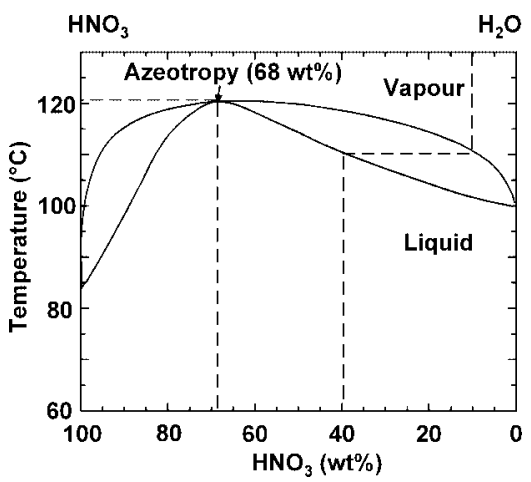

Fig. 2. Phase diagram of nitric acid and water. Reprinted with permission from ref. 2. (C2003 by American Institute of Physics.

として, ポーラスな膜が堆積する, 久陥準位密度が高 い，尖頭部では膜厚が薄くなる，プラズマダメージがあ る, C の含有率が比較的高い, $\mathrm{Si}$ 表面を直接酸化して いるわけではないので界面準位密度が高いなどがあげら れている ${ }^{1)}$ 。そこで，良質なゲート絶縁膜を形成するた めに，新たな低温酸化膜形成法の開発が期待されてき た。

我々は，化学酸化膜に注目し，半導体工場で広く使用 されている薬液の中で，硝酸，特に共沸硝酸を用いて形 成される $\mathrm{SiO}_{2}$ 膜が良好な電気特性示すことを見出し た ${ }^{2,3)}$ 。共沸硝酸とは, Fig. 2 の硝酸水溶液の相図に見ら れるように，気体と液体の組成が等しく，沸点が最も高 くなる組成の硝酸である ${ }^{2)}$ 。共沸硝酸の濃度は $68 \mathrm{wt} \%$

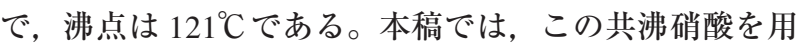
いた $\mathrm{Si}$ 表面上への〜 $1 \mathrm{~nm}$ の膜厚の極薄 $\mathrm{SiO}_{2}$ 薄膜の形 成と, 低濃度の硝酸と共沸硝酸を用いた二段階硝酸酸化 法 ${ }^{4,5)}$ による〜 $10 \mathrm{~nm}$ 以上の膜厚の $\mathrm{SiO}_{2}$ 膜の形成に関す る研究について紹介する。

\section{2. 一段階硝酸酸化法を用いて形成した〜1 nm の膜厚の極薄 $\mathrm{SiO}_{2}$ 膜}

実験には,リンをドープした $n-S i(100)$ ウェーハを用 いた。 $\mathrm{Si}(100)$ 表面を RCA 洗浄法 ${ }^{6}$ により清浄化し，形 成された $\mathrm{SiO}_{2}$ 膜を希フッ化水素酸水溶液によりエッチ

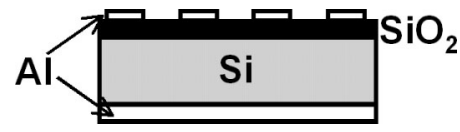

Fig. 3. Schematic model of $<\mathrm{Al} / \mathrm{SiO}_{2} / \mathrm{Si}(100)>\mathrm{MOS}$ structure used for measurement of $I-V$ and $C-V$ curves and PMA treatment.

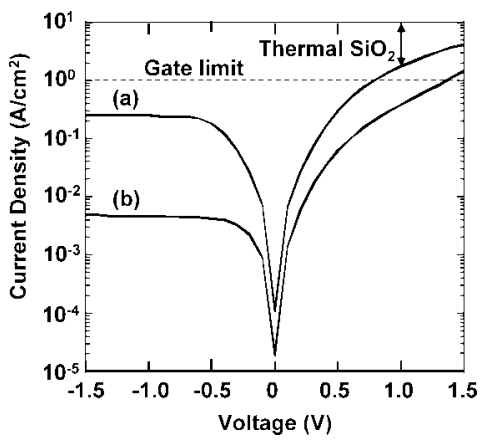

Fig. 4. $I-V$ curves for the $<\mathrm{Al} / 1.4 \mathrm{~nm}-\mathrm{SiO}_{2} / \mathrm{Si}(100)>\mathrm{MOS}$ diodes with the $\mathrm{SiO}_{2}$ layer formed in $68 \mathrm{wt} \% \mathrm{HNO}_{3}$ at $121^{\circ} \mathrm{C}$ : (a) before PMA. (b) after PMA at $200^{\circ} \mathrm{C}$. The arrow indicates typical range of leakage current density for $\sim 1.5 \mathrm{~nm}$ thermal oxide. Reprinted with permission from ref. 3. (02002 by American Institute of Physics.

ングした後， $68 \mathrm{wt} \%$ の共沸硝酸溶液中 $121^{\circ} \mathrm{C}$ で 30 分酸 化した。この表面の X 線光電子分光 (XPS) スペクト ルを測定すると, $\mathrm{Si}$ 基板の $\mathrm{Si}^{0}$ および $\mathrm{SiO}_{2}$ 薄膜の $\mathrm{Si}^{4+}$ の二つの Si $2 p$ のピークが観測された。これらのピーク 面積の比から，この酸化膜厚は， $1.4 \mathrm{~nm}$ と見積もられ た ${ }^{3,7)}$ 。酸化時間を 10 分から 6 時間まで変化させても膜 厚が変化しなかったので, 短時間で安定な $\mathrm{SiO}_{2}$ 薄膜が 生成したと考えられる ${ }^{2)}$ 。

この表面と裏面に Fig. 3 のような $\mathrm{Al}$ 電極を蒸着した 後, $<\mathrm{Al} / \mathrm{SiO}_{2} / \mathrm{Si}(100)>\mathrm{MOS}$ ダイオードの電気特性を評 価した。一段階硝酸酸化法により形成した $\mathrm{SiO}_{2}$ 薄膜の リーク電流密度は, Fig. 4 (a) に見られるように, $1 \mathrm{~V}$

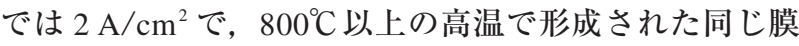
厚の熱酸化膜の值に匹敵した。さらに, $<\mathrm{Al} / \mathrm{SiO}_{2} / \mathrm{Si}$ (100) >MOS ダイオード構造を $5 \mathrm{vol} \%$ 水素中で加熱する PMA（Post Metallization Annealing）処理を $\mathrm{Al}$ 電極が極 薄 $\mathrm{SiO}_{2}$ 膜と反応せずに最もリーク電流が低くなる $200^{\circ} \mathrm{C}$ で行った。この時, 膜厚が $1.3 \mathrm{~nm}$ と少し減少した が, Fig. 4（b）のように, リーク電流密度が大幅に低減 し， $1 \mathrm{~V}$ では $0.4 \mathrm{~A} / \mathrm{cm}^{2}$ であった ${ }^{3,8)}$ 。これにより， $1 \mathrm{~V}$ 駆動のトランジス夕なら，この硝酸酸化 $\mathrm{SiO}_{2}$ 薄膜がゲ 一ト絶縁膜として利用できる領域 ${ }^{9}$ に達していることが わかった。

一段階硝酸酸化法により形成した $\mathrm{SiO}_{2}$ 薄膜の電気容 


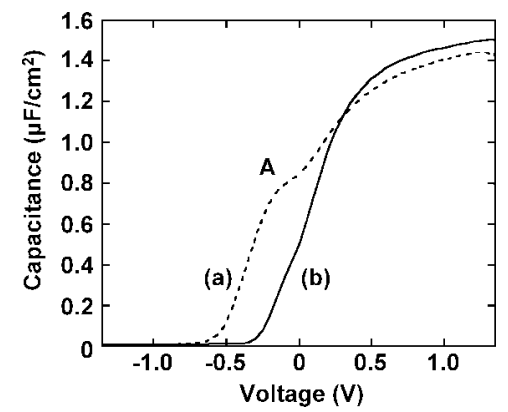

Fig. 5. $C$ - $V$ curves for the $<\mathrm{Al} / 1.4 \mathrm{~nm}-\mathrm{SiO}_{2} / \mathrm{Si}(100)>\mathrm{MOS}$ diodes with the $\mathrm{SiO}_{2}$ layer formed in $68 \mathrm{wt} \% \mathrm{HNO}_{3}$ at $121^{\circ} \mathrm{C}$ : (a) before PMA. (b) after PMA at $200^{\circ} \mathrm{C}$. Reprinted with permission from ref. 3. (02002 by American Institute of Physics.

量-電圧（C-V）曲線には, Fig.5 (a) の A に見られる ようなショルダーが現れた。これは, 価電子带と伝導帯 の間に界面準位があることを示している ${ }^{10)}$ 。界面準位の 原因の一つとして, $\mathrm{SiO}_{2}$ と $\mathrm{Si}$ の格子定数の違い等によ り生じる $\mathrm{Si}$ ダングリングボンドの存在が考えられてい る。PMA 後では, ショルダー A が消えており, Si ダン グリングボンドが $\mathrm{H}$ 原子と結合し, 界面準位が消滅し たと考えられる ${ }^{10,11)}$ これは, PMA によるリーク電流 密度の減少の一原因と考えられる ${ }^{12)}$ 。また, 固定電荷 は, 観測した $C-V$ 曲線から求めたフラットバンド電位 $(-0.3 \mathrm{~V})$ と理論值 $(-0.25 \mathrm{~V}, n-\mathrm{Si}$ と $\mathrm{Al}$ の仕事関数の 差）の差より, 正の電荷で密度は $10^{11} \mathrm{~cm}^{-2}$ オーダーで あることがわかった ${ }^{13,14)}$ 。

このように，一段階硝酸酸化法を用いて，リーク電流 密度の低い良質な極薄 $\mathrm{SiO}_{2}$ 膜を形成できる。近年, 高 誘電体である $\mathrm{Hf}$ 酸化膜と $\mathrm{Si}$ 基板の界面に, 絶縁性の高 い $1 \mathrm{~nm}$ 以下のバッファ膜を挿入する積層構造のゲート 絶縁膜の研究が多く行われている。一段階硝酸酸化法を 用いて形成した酸化膜が，このバッファ膜に適用できる 可能性が高い。一方, 凹凸の大きい poly-Si 表面上に形 成される TFT 用ゲート絶縁膜としては, 膜厚が不十分 である。これは, 以下に示す二段階硝酸酸化法によって 解決される。

\section{3. 二段階硝酸酸化法を用いて形成した〜10 $\mathrm{nm}$ 以上の膜厚の $\mathrm{SiO}_{2}$ 膜}

\section{3. $1 \mathrm{SiO}_{2}$ 膜の形成と構造}

濃度が $40 \mathrm{wt} \%$ と $68 \mathrm{wt} \%$ の硝酸を用いる二段階硝酸酸 化法を用いると, 最も酸化膜の形成速度が大きくなるこ とがわかった4)。Fig. 6 に共沸硝酸を用いての二段階目 の硝酸酸化をガラス基板上の poly-Si 薄膜について 2, 3 および 5 時間行った後, 測定したXPS スペクトルを示

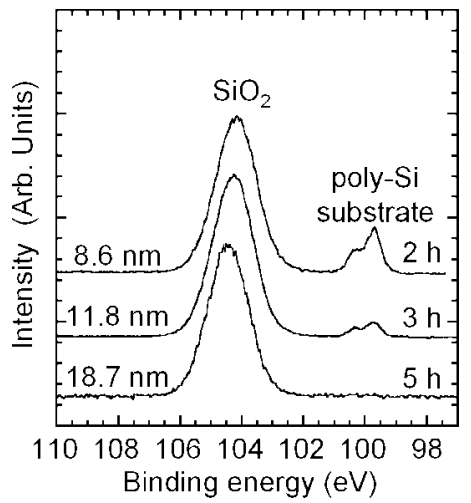

Fig. 6. Si $2 p$ XPS spectra for the $\mathrm{SiO}_{2}$ films formed by use of the two-step NAOS method on poly-Si. The thickness is calculated from the peak-area ratio of the poly-Si substrate to the $\mathrm{SiO}_{2}$ film.

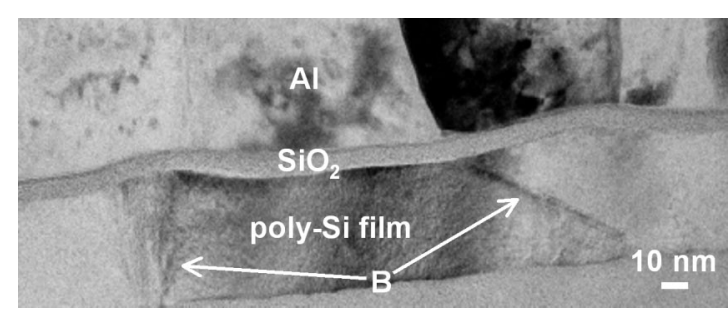

Fig. 7. TEM micrograph of a $\mathrm{SiO}_{2}$ film formed on a poly-Si thin film by the two-step NAOS method at $121^{\circ} \mathrm{C}$. B indicates crystal boundaries of poly-Si. Reprinted with permission from ref. 4. (C2006 by Elsevier B.V.

す。鋭いダブレットピークは, poly-Si の $\mathrm{Si} 2 p_{3 / 2}$ と $\mathrm{Si}$ $2 p_{1 / 2}$ に, ブロードなピークは, $\mathrm{SiO}_{2}$ 膜の $\mathrm{Si} 2 p$ に帰属さ れる。これらのピーク面積比から, 各酸化時間後の膜厚 は，それぞれ， $8.6 \mathrm{~nm}, 11.8 \mathrm{~nm}$ 抢よび $18.7 \mathrm{~nm}$ と見積 もられた。

Fig. 7 に, 二段階硝酸酸化法により形成した $\mathrm{SiO}_{2} /$ poly-Si の断面 TEM 像を示す。硝酸酸化前の poly-Si に は, a-Si をレーザーアニールにより溶融結晶化した際に 生成した結晶界（B）やリッジが観察された。二段階目 の硝酸酸化を 100 分行った後には，このように凹凸のあ る poly-Si 表面上でも， ９ $\mathrm{nm}$ のほほ均一な膜厚の $\mathrm{SiO}_{2}$ 膜が形成されていることがわかった。一方, CVD 法に より形成した $\mathrm{SiO}_{2}$ 膜は, 凸部の膜厚が薄くなる。また, 熱酸化膜が使用できたとしても，均一な酸化膜の形成は 難しいと考えられる。なぜなら, poly-Si 表面は結晶粒 により結晶方位が異なり, 熱酸化法では酸化膜成長の面 方位依存性があるからである ${ }^{15}$ 。 $\mathrm{Si}$ (111) 表面の方が $\mathrm{Si}$ (100) 表面より酸化膜の形成速度が 1.7 倍大きく, これ は表面原子密度が異なるためと解釈されている。これに 対し, 二段階硝酸酸化法では, Table 1 に示すように酸 化膜の形成速度に面方位依存性はない4)。このように, 
二段階硝酸酸化法は, 粗面 poly- $\mathrm{Si}$ 上に均一な $\mathrm{SiO}_{2}$ 膜を 形成できることが明らかになった。

\section{$3.2 \sim 10 \mathrm{~nm}$ の $\mathrm{SiO}_{2}$ 膜の原子密度}

Fig. 8 に, $n-\mathrm{Si}(100)$ 表面上に二段階硝酸酸化法により 形成した $9.3 \mathrm{~nm}$ の $\mathrm{SiO}_{2}$ 膜のフーリエ変換赤外 $(\mathrm{FT}-$ IR）吸収スペクトルを示す。〜 $1250 \mathrm{~cm}^{-1}$ と〜1070 $\mathrm{cm}^{-1}$ にピークが観測され，それぞれ $\mathrm{Si}-\mathrm{O}-\mathrm{Si}$ 非対称伸縮振動 の LO, TO フォノンに帚属される。TOおよび LO フォ ノンの振動数 $\nu_{T O}$ および $\nu_{L O}$ は, それぞれ, 以下の式で 表される ${ }^{16)}$ 。

$$
\begin{gathered}
\nu_{T O}=\frac{1}{2 \pi} \sqrt{2\left[\alpha \sin ^{2}(\theta / 2)+\beta \cos ^{2}(\theta / 2)\right] / \mathrm{m}} \\
\nu_{L O} \\
=\frac{1}{2 \pi} \sqrt{2\left[\alpha \sin ^{2}(\theta / 2)+\beta \cos ^{2}(\theta / 2)+Z^{2} \rho / \varepsilon_{\infty}(2 m+M)\right] / m}
\end{gathered}
$$

ここで, $\alpha$ と $\beta$ は中心的と非中心的な力の定数, $\theta$ は Si-O-Si の結合角, $m$ と $M$ は $\mathrm{Si}$ と O の原子の質量, $\varepsilon_{\infty}$ は真空の絶対誘電率, $Z$ は $O$ 原子の運動により誘起さ れる電荷量, $\rho$ は $\mathrm{SiO}_{2}$ の原子密度である。 $C$ を定数と すると式 (1)および式 ( 2 )より,

$$
C \rho=\nu_{L O}^{2}-\nu_{T O}^{2}
$$

Table 1. Thickness of $\mathrm{SiO}_{2}$ layers after two-step NAOS on n-type $\mathrm{Si}(100)$ and $\mathrm{Si}(111)$ surfaces. Reprinted with permission from ref. 4. (02006 by Elsevier B.V.

\begin{tabular}{lcc}
\hline \multicolumn{1}{c}{ substrate } & $\begin{array}{c}\text { oxidation time } \\
(\mathrm{h})\end{array}$ & $\begin{array}{c}\text { thickness of oxide } \\
(\mathrm{nm})\end{array}$ \\
\hline$n-\mathrm{Si}(100) \sim 10 \Omega \mathrm{cm}$ & 4 & 5.8 \\
$n-\mathrm{Si}(111) \sim 8 \Omega \mathrm{cm}$ & 4 & 6.2 \\
$n-\mathrm{Si}(100) \sim 10 \Omega \mathrm{cm}$ & 5 & 7.0 \\
$n-\mathrm{Si}(111) \sim 8 \Omega \mathrm{cm}$ & 5 & 6.7 \\
\hline
\end{tabular}

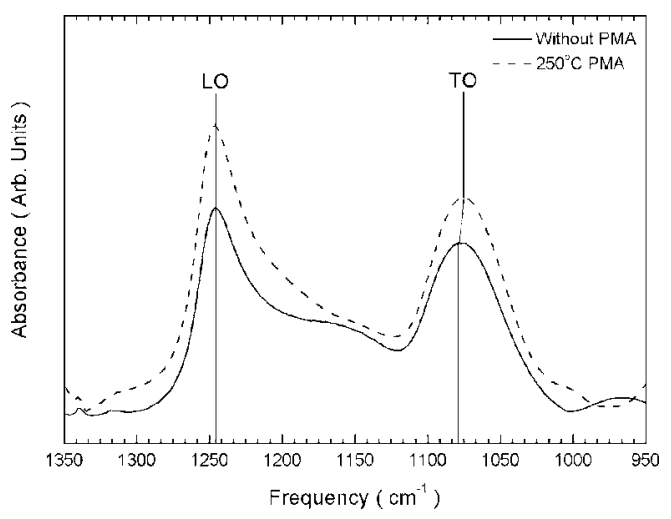

Fig. 8. FT-IR spectra of the $\mathrm{SiO}_{2} / \mathrm{Si}(100)$ structure formed by the two-step NAOS method at $121^{\circ} \mathrm{C}$ : without and with PMA in $5 \mathrm{vol} \% \mathrm{H}_{2}$ at $250^{\circ} \mathrm{C}$. Reprinted with permission from ref. 1. (C2008 Elsevier B.V.
と表せる。ここで, $40 \mathrm{~nm}$ の熱酸化膜で報告されている $\nu_{T O}=1090 \mathrm{~cm}^{-1}, \quad \nu_{L O}=1260 \mathrm{~cm}^{-1}$ および $\rho=2.28 \times 10^{22}$ $\mathrm{cm}^{-3}$ の值を用いると ${ }^{16)}$, 硝酸酸化膜の原子密度は, PMA 前後でそれぞれ $2.30 \times 10^{22} \mathrm{~cm}^{-3}$ および $2.32 \times 10^{22}$ $\mathrm{cm}^{-3}$ と求められた。このように, 二段階硝酸酸化によ り形成した $\mathrm{SiO}_{2}$ 膜は熱酸化膜に匹敵する緻密な膜であ った。また, 水素中 PMA 処理には, 界面準位を消滅さ せるだけではなく, $\mathrm{SiO}_{2}$ 膜を緻密にする効果もあるこ とがわかった。

\section{$3.3 \sim 10 \mathrm{~nm}$ の $\mathrm{SiO}_{2}$ 膜の電気特性評価}

$n-\mathrm{Si}(100)$ 表面上に二段階硝酸酸化法により形成した $\mathrm{SiO}_{2}$ 膜を持つ $<\mathrm{Al} / 9.3 \mathrm{~nm}-\mathrm{SiO}_{2} / \mathrm{Si}(100)>\mathrm{MOS}$ ダイオー ド構造の電気特性を測定した ${ }^{1)}$ 。 $\mathrm{SiO}_{2}$ 膜を流れるリーク 電流密度は, Fig.9（a）に見られるように，1 Vでは, $10^{-8} \mathrm{~A} / \mathrm{cm}^{2}$ であった。しかし，5vol\% 水素中や 100 $\mathrm{vol} \%$ 水素中で最もリーク電流密度が低くなる $250^{\circ} \mathrm{C} に$ て PMA を行うと, それぞれ, Fig. 9 (b) および (c) が 示すようにリーク電流密度が，それぞれ， $3 \times 10^{-9} \mathrm{~A} /$ $\mathrm{cm}^{2}$ および $1 \times 10^{-9} \mathrm{~A} / \mathrm{cm}^{2}$ に低減した。このように, CVD 膜のリーク電流密度より小さく, 熱酸化膜のリー ク電流密度に匹敵するリーク特性が得られた。

二段階硝酸酸化により形成した $\mathrm{SiO}_{2}$ 膜の $C-V$ 曲線に は，一段階硝酸酸化法により形成した $\mathrm{SiO}_{2}$ 薄膜と同様 にショルダーCが現れたが（Fig. 10 (a)），PMA により 消失した（Fig. 10（b））。これは，PMAによって Si ダ ングリングボンドから Si-H 結合が形成され, PMA によ るリーク電流密度の減少の一原因になったと考えられ る $^{16)}$ 。また, 固定電荷は, 観測した $C-V$ 曲線から求め たフラットバンド電位 $(-0.55 \mathrm{~V})$ と理論值 $(-0.25 \mathrm{~V}$, $n$-Si と $\mathrm{Al}$ の仕事関数の差) の差より, 正の電荷で密度 は $10^{11} \mathrm{~cm}^{-2}$ オーダーであることがわかった ${ }^{13,14)}$ 。

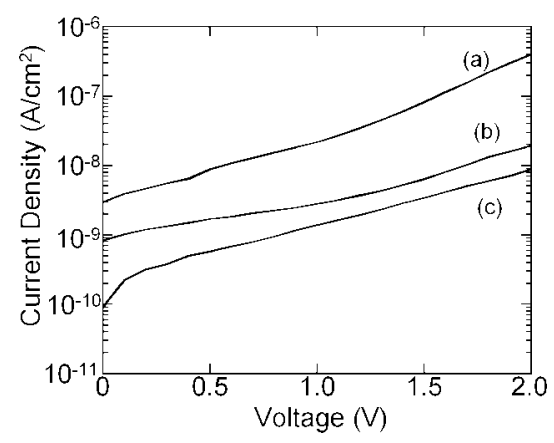

Fig. 9. $I-V$ curves of the $<\mathrm{Al} / 9.3 \mathrm{~nm}-\mathrm{SiO}_{2} / \mathrm{Si}(100)>\mathrm{MOS}$ diodes with the $\mathrm{SiO}_{2}$ layer formed by the two-step NAOS method at $121^{\circ} \mathrm{C}$ : (a) without PMA ; (b) with PMA in $5 \mathrm{vol} \% \mathrm{H}_{2}$ at $250^{\circ} \mathrm{C}$; (c) with PMA in pure $\mathrm{H}_{2}$ at $250^{\circ} \mathrm{C}$. Reprinted with permission from ref. 1 . C)2008 Elsevier B.V. 


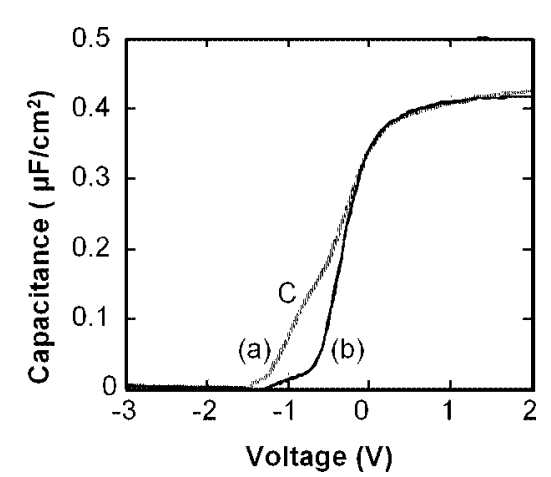

Fig. 10. $C-V$ curves of the $<\mathrm{Al} / 9.3 \mathrm{~nm}-\mathrm{SiO}_{2} / \mathrm{Si}(100)>\mathrm{MOS}$ diodes with the $\mathrm{SiO}_{2}$ layer formed by the two-step NAOS method at $121^{\circ} \mathrm{C}$ : (a) with no PMA; (b) with PMA in pure $\mathrm{H}_{2}$ at $250^{\circ} \mathrm{C}$. Reprinted with permission from ref. 1. (C2008 Elsevier B.V.

\section{4. 大型 TFT ガラスの硝酸酸化装置の開発}

基礎実験の後，これらの硝酸酸化法が実際のデバイス 作成に応用できるかを検討しなければならない。なぜな ら, 酸化膜の大面積での均一性や清浄性などが問題にな りえるからである。そこで, $32 \mathrm{~cm} \times 40 \mathrm{~cm}$ の大きさの TFT ガラス基板を NAOS 処理できる装置を開発し, LSI を形成できる $3 \times 10^{9}$ atoms $/ \mathrm{cm}^{2}$ 以下の金属污染のレベ ルを確保している。また, Fig. 11 に示したように, 酸 化膜厚も, 一段階硝酸酸化後および二段階硝酸酸化後 で，均一であることがわかった ${ }^{17)}$

\section{5.おわりに}

一段階硝酸酸化法により, Si 表面上にリーク電流密 度の小さい〜 $1 \mathrm{~nm}$ の膜厚の極薄 $\mathrm{SiO}_{2}$ 膜を低温形成でき る。また，二段階硝酸酸化法により，凹凸のある poly$\mathrm{Si}$ 表面に〜 $10 \mathrm{~nm}$ 以上の均一な膜厚の $\mathrm{SiO}_{2}$ 膜も低温形 成できる。いずれの $\mathrm{SiO}_{2}$ 薄膜も, 水素中で加熱して界 面準位の消滅や膜の緻密化を行うことにより, 熱酸化膜 に匹敵するまたはそれ以上の性能を示し, 硝酸酸化膜を ゲート酸化膜に応用することが可能であることが示され た。

今後は, $\mathrm{SiO}_{2}$ 膜の形成メカニズムを解明すると共に, よりリーク電流密度の低い $\mathrm{SiO}_{2}$ 膜をより高速に形成す る条件を探索する予定である。また, ゲート絶縁膜に は, リーク電流密度だけでなく, 移動度 $(\mu)$ や間值下 特性（S 值, sub-threshold swing）などの重要な性能の指 標がある。今後, 実際にトランジス夕を試作し, 多面的 な評価を行う予定である。さらに，本稿では述べなかっ たが，ゲート絶縁膜の薄膜化と高品質化は，デバイスの 駆動電圧の低減を可能とし, さらなる省電力化が期待で (a)
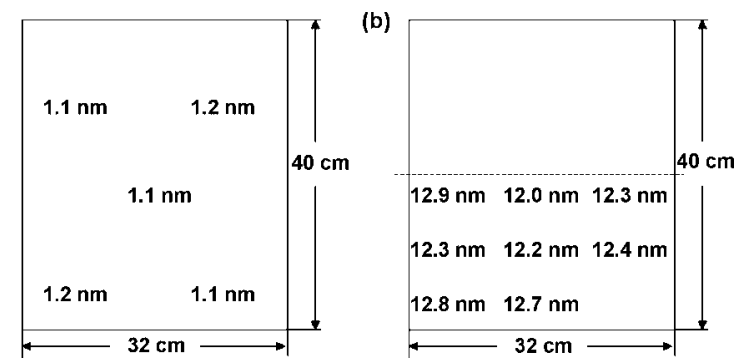

Fig. 11. Thickness distribution of the $\mathrm{SiO}_{2}$ layers formed on $32 \mathrm{~cm} \times 40 \mathrm{~cm}$ poly-Si substrate : (a) by use of onestep NAOS ; (b) by use of two-step NAOS. Reprinted with permission from ref. 17. (C2008 Elsevier B.V.

きる。最適な新規回路の開発も含めて, 試作 LCD によ る最終的な性能評価も行う予定である。

\section{文献}

1) S. Imai, S. Mizushima, Asuha, W.-B. Kim and H. Kobayashi : Appl. Surf. Sci., in press.

2) H. Kobayashi, Asuha, O. Maida, M. Takahashi and $H$. Iwasa : J. Appl. Phys. 94, 7328 (2003).

3) Asuha, T. Kobayashi, O. Maida, M. Inoue, M. Takahashi, Y. Todokoro and H. Kobayashi : Appl. Phys. Lett. 81, 3410 (2002).

4) Asuha, S.-S. Im, M. Tanaka, S. Imai, M. Takahashi and H. Kobayashi : Surf. Sci. 600, 2523 (2006).

5) Asuha, S. Im, M. Tanaka, S. Imai, M. Takahashi and H. Kobayashi : J. Appl. Phys 85, 3783 (2004).

6) W. Kern and D.A. Pluotinen : RCA Rev. 31, 187 (1970).

7) F.J. Himpsel, F.R. McFeel, A. Taleb-Ibrahimi, J.A. Yarmoff and G. Hollinger: Phys. Rev. B 38, 6084 (1988).

8) Asuha, T. Yuasa, O. Maida and H. Kobayashi : Appl. Phys. Lett. 80, 4175 (2002).

9) A.I. Kingon, J.-P. Maria and S.K. Striffer : Nature 406, 1032 (2000).

10) M. Depas, R.L. Van Meirhaeghe, W.H. Laflère and F. Cardon : Solid-State Electron 37, 433 (1994).

11) M.L. Reed and J.D. Plummer : J. Appl. Phys. 63, 5776 (1998).

12) T. Ono, Y. Egami, K. Kutsuki, H. Watanabe and K. Hirose : J. Phys. : Condens, Matter 19, 365202 (2007).

13) D.K. Schroder: "Semiconductor Material and Device Characterization" (John Wiley \& Sons, Inc. Hoboken, New Jersey, 2006).

14) S.M. Sze and K.K. Ng: "Physics of Semiconductor Devices”(John Wiley \& Sons, Inc. Hoboken, New Jersey, 2007).

15) B.E. Deal : Solid State Sci. Technol. 125, 576 (1978).

16) C. Martinet and R.A.B. Devine : J. Appl. Phys. 77, 4343 (1995).

17) S. Mizushima, S. Imai, Asuha, M. Tanaka and $H$. Kobayashi : Appl. Surf. Sci. 254, 3685 (2008). 